\title{
Erythroderma: A clinico-etiological study of 58 cases in a tertiary hospital of North India
}

\author{
Nadia Shirazi ${ }^{1}$, Rashmi Jindal ${ }^{2}$, Akanksha Jain $^{2}$, Kanika Yadav ${ }^{3}$, Sohaib Ahmad $^{4}$ \\ ${ }^{1}$ Associate Professor, ${ }^{3}$ Resident, Department of Pathology, Himalayan Institute of Medical Sciences, Jolly Grant, Dehradun, Uttarakhand, \\ India, ${ }^{2}$ Assistant Professor, Department of Dermatology \& Venereology, Himalayan Institute of Medical Sciences, Jolly Grant, Dehradun, \\ Uttarakhand, India, ${ }^{4}$ Professor, Department of Medicine, Himalayan Institute of Medical Sciences, Jolly Grant, Dehradun, Uttarakhand, India
}

\section{A B S TRA C T}

Background: Erythroderma (exfoliative dermatitis) is a cutaneous reaction pattern characterized by generalized erythema and scaling which can be seen in a wide range of cutaneous or systemic diseases. It is important to establish correct diagnosis whenever possible so that specific therapy may be initiated. The study was undertaken to evaluate the clinical profile and etiology of erythroderma and to correlate clinical diagnosis with histopathological findings. Methods: A retrospective study was done in the Department of Pathology. Fifty eight cases of erythroderma diagnosed clinically in the past 5 years were studied and their epidemiological, clinical, laboratory and histopathological findings were analyzed. Results: The mean age of presentation was 39.3 years and male to female ratio was 3:2. Apart from erythema and scaling that were present in all patients, pruritis ( $n=40,69 \%)$, edema ( $n=12,20.2 \%)$ and fever $(n=11,19 \%$ ) were the most common symptoms at presentation. The most common etiology of exfoliative dermatitis was drug reactions $(n=19,32.7 \%)$ followed by atopic dermatitis $(n=12,20.6 \%)$ and erythrodermic psoriasis $(n=10,7.2 \%)$. Other causes were Mycosis Fungoides, Allergic/Air borne contact dermatitis, Lichen Planus, Pityriasis Rubra Pilaris. There was no significant contribution of laboratory data and all the patients were HIV negative. The best clinicopathological correlation (100\%) was found in erythrodermic psoriasis and Mycosis Fungoides. Conclusion: Erythroderma often obscures the primary lesion. Clinicians should evaluate all cases of erythroderma by eliciting proper clinical history, taking biopsies and performing other ancillary haematological investigations. Hospitalization may be required as the disease carries risk of significant mortality.

Key words: Erythroderma, Causes, Drug reaction, Indian patients
Access this article online Website:

http://nepjol.info/index.php/AJMS DOI: 10.3126/ajms.v6i6.12265

\section{INTRODUCTION}

Erythroderma or exfoliative dermatitis is a rare skin disorder characterized by erythema and scaling involving $>90 \%$ of body surface area. Erythroderma is not a specific diagnosis but the clinical manifestation of a variety of underlying diseases. The estimated annual incidence is 1 to 2 patients per 100,000 population. ${ }^{1}$ It is more common in males and is usually seen in elderly patients however age of onset is primarily related to etiology. Most cases of erythroderma in younger patients are due to atopic dermatitis. Many times erythroderma is the manifestation of an underlying skin disorder like psoriasis, atopic dermatitis, pityriasis rubra pilaris or actinic dermatosis. It may be related to drug intake, idiopathic or due to underlying malignancies. It usually evolves slowly over months to years except for drug reactions and atopy which tend to develop more acutely. Common clinical symptoms include fever, chills, malaise and pruritis along with peripheral edema, lymphadenopathy and secondary skin infections. It is important to establish correct diagnosis because specific therapy other than corticosteroids or anti-inflammatory treatment may be necessary to improve patient's condition. Erythroderma carries a significant risk of mortality and morbidity and accounts for upto $1 \%$ of all dermatological hospital admissions. 
There are very few published studies on erythroderma in Indian patients particularly from the north Indian hilly state of Uttarakhand. We aimed to study the clinical profile and etiology of erythroderma and correlate the clinical diagnosis with histopathological findings in this part of the country.

\section{MATERIAL AND METHODS}

This study was performed retrospectively in the Department of Pathology. All consecutive cases diagnosed clinically as erythroderma in past 5 years from January 2010 to December 2014 were studied. We analyzed and tabulated their epidemiological, clinical, laboratory and histological data from the hospital records and analyzed their relationship to etiology of erythroderma.

\section{RESULTS}

The incidence of erythroderma in our dermatology clinic was $0.9 \%$. Fifty eight cases of eythroderma were seen out of a total of 464 skin biopsies received during last 5 years. The male to female ratio was 3:2. Age of patients ranged from 14 years to 78 years. The mean age of presentation was 39.2 years. Erythema and scaling were seen in all patients followed by pruritis ( $n=40,69 \%)$, peripheral edema $(n=12,20 \%)$ and fever $(n=11,19 \%)$. The onset of these symptoms was gradual taking about 2-3 weeks to develop except in cases of drug reactions where it was acute and patients presented with complains developing within 24-48 hours. The most common etiology behind development of erythroderma was drug reaction ( $\mathrm{n}=19,32.7 \%)$. (Table 1, Microphotograph 1). The offending drugs were not known to the patient in $26.3 \%$ cases where they had taken over the counter drugs for fever or pain. Carbamazepine and sulfasalazine were other agents causing $15.8 \%$ cases each of drug induced erythroderma (Table 2). This group of erythroderma had a good prognosis with rapid resolution after withdrawal of offending drugs. Atopic dermatitis ( $\mathrm{n}=12,20.6 \%$ ) was seen mostly in younger people with mean age of presentation being 18 years. Such patients had a personal/ family history of atopy (asthma, allergic rhinitis, atopic dermatitis). Erythrodermic psoriasis $(\mathrm{n}=10,17.2 \%)$ was seen in patients with pre existing psoriasis who gave history of irregular use of medications or stoppage of all treatment (Figure 1, Microphotograph 2). In 10.3\% cases no cause of erythroderma could be established. Skin biopsy was not rewarding in these cases and showed only mild spongiosis and acanthosis. Mycosis fungoides was diagnosed in 2 cases (Microphotograph 3). Immunohistochemistry was done in both cases which showed CD30 and CD3 positivity in large atypical lymphoid cells (Microphotograph 4). Allergic contact dermatitis produced by occupational exposure to chemicals was seen in 2 cases (Figure 2). Clinical diagnosis was Air Borne Contact Dermatitis in both these lesions. Two cases each of Lichen planus (LP) and Pityriasis rubra pilaris (PRP) were also diagnosed on histopathology. Clinical impression was chronic atopic dermatitis in both

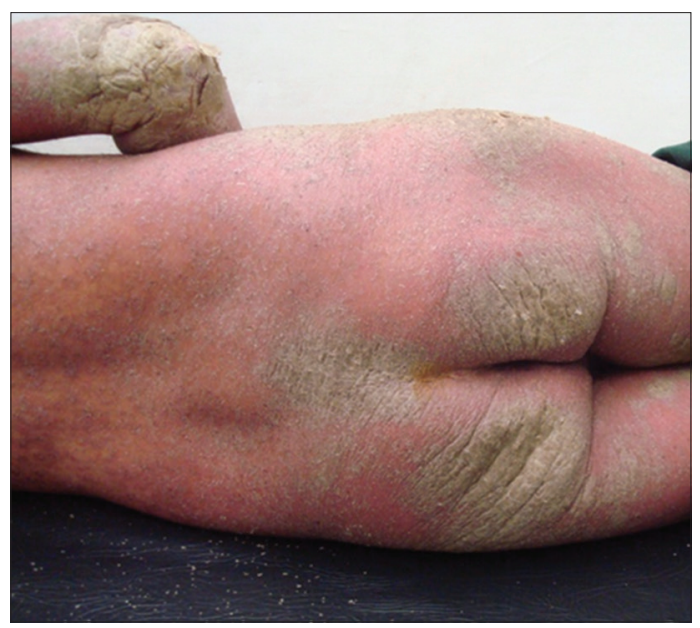

Figure 1: Erythrodermic psoriasis

\begin{tabular}{|c|c|c|c|c|}
\hline S. no. & Causes & $\mathbf{n}, \%$ & Mean age (years) & Pathological features \\
\hline 1. & Drug induced & $19,32.7$ & 37 & Epidermal spongiosis, occasional eosinophils in upper dermis \\
\hline 2. & Atopic & $12,20.6$ & 48 & $\begin{array}{l}\text { Some intercellular edema in epidermis with mild perivascular } \\
\text { inflammatory infiltrate. Exocytosis and few mast cells seen }\end{array}$ \\
\hline 3. & Erythtrodermic psoriasis & $10,17.2$ & 44 & $\begin{array}{l}\text { Patchy parakeratosis, Psoriasiform hyperplasia and few dilated } \\
\text { capillaries in superficial dermis }\end{array}$ \\
\hline 4. & Idiopathic & $6,10.3$ & 56 & Mild spongiosis and moderate acanthosis \\
\hline 5. & Mycosis fungoides & $2,3.4$ & 39 & $\begin{array}{l}\text { Band like dermal inflammatory infiltrate comprising of atypical } \\
\text { lymphocytes. Pautrier microabscess are seen }\end{array}$ \\
\hline 6. & Allergic contact dermatitis & $2,3.4$ & 28 & Spongiotic epidermis with exocytosis of lymphocytes and few eosinophils \\
\hline 7. & Lichen planus & $2,3.4$ & 56 & $\begin{array}{l}\text { Saw-toothing of rete pegs with band like inflammatory infiltrate and few } \\
\text { Civatte bodies }\end{array}$ \\
\hline 8. & Pityriasis rubra pilaris & $2,3.4$ & 35 & Alternating orthokeratosis and parakeratosis \\
\hline 9. & Seborrheic dermatosis & $1,1.7$ & 42 & Spongiosis, irregular acanthosis, inflammatory infiltrate \\
\hline 10. & Phototoxic dermatitis & $1,1.7$ & 18 & Ballooning of keratinocytes with mild epidermal necrosis \\
\hline 11. & Sarcoidosis & $1,1.7$ & 28 & Non necrotizing granulomas \\
\hline
\end{tabular}


cases of LP while it was psoriasis in one case of PRP. One case each of Seborrheic dermatitis, photodermatosis and non necrotizing granulomatous inflammation were seen. Sarcoidosis was rendered as a diagnosis of exclusion in the latter case.

Mild anemia, raised ESR, leukocytosis and hypoalbuminemia were common laboratory findings however nothing contributory to finding underlying cause of erythroderma could be found. All our patients were non-reactive for HIV.

\begin{tabular}{llc}
\multicolumn{3}{l}{ Table 2: Drugs causing erythroderma $(\mathbf{n}=19)$} \\
\hline Serial no. & Drug & No. of cases, (\%) \\
\hline 1. & Unknown & $5,(26.3)$ \\
2. & Carbamazepine & $3,(15.8)$ \\
3. & Sulfasalazine & $3,(15.8)$ \\
4. & Ayurvedic/homeopathic & $2,(10.5)$ \\
5. & Allopurinol & $2,(10.5)$ \\
6. & Phenytoin & $1,(5.3)$ \\
7. & Etoricoxin & $1,(5.3)$ \\
8. & Sodium valproate & $1,(5.3)$ \\
9. & ATT (INH ) & $1,(5.3)$ \\
\hline
\end{tabular}

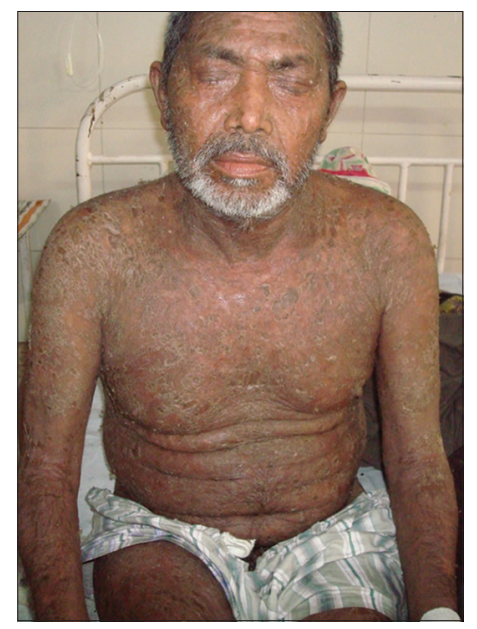

Figure 2: Air borne contact dermatitis presenting as erythroderma

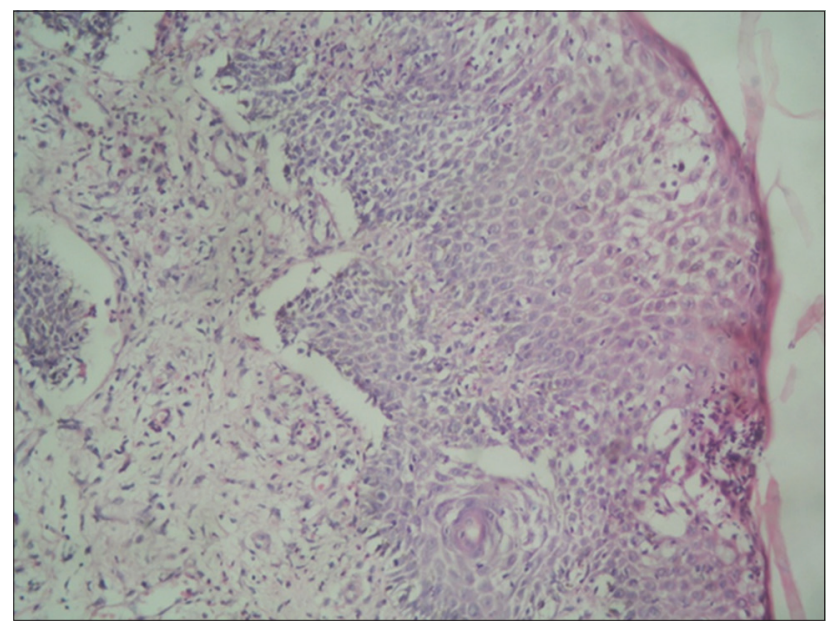

Microphotograph 1: H\&E: 20x10X: Epidermal spongiosis in drug induced erythroderma

\section{DISCUSSION}

Erythroderma is a rare exfoliative skin disorder, the true incidence of which remains unknown. It is uncommon with

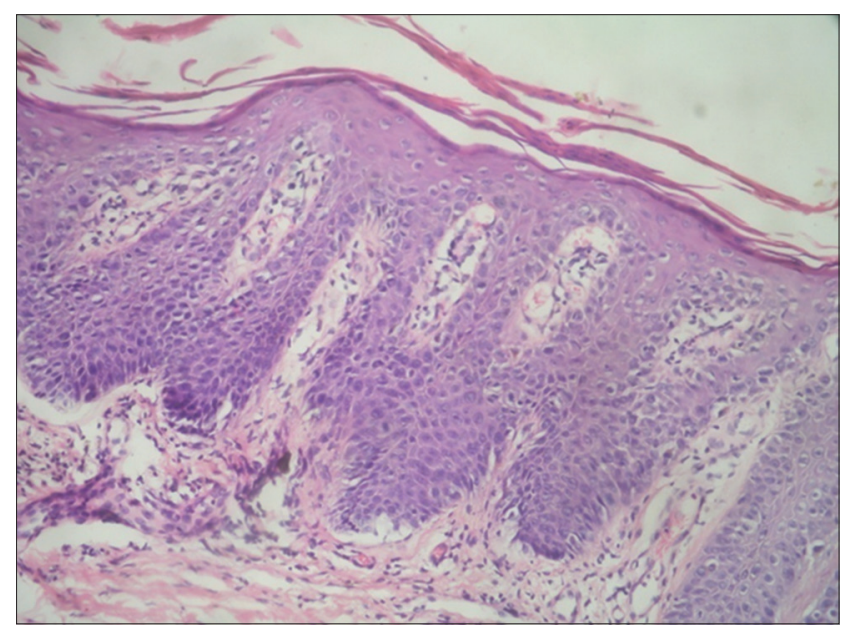

Microphotograph 2: H\&E: 20x10X: Epidermal hyperplasia and patchy parakeratosis in erythrodermic psoriasis

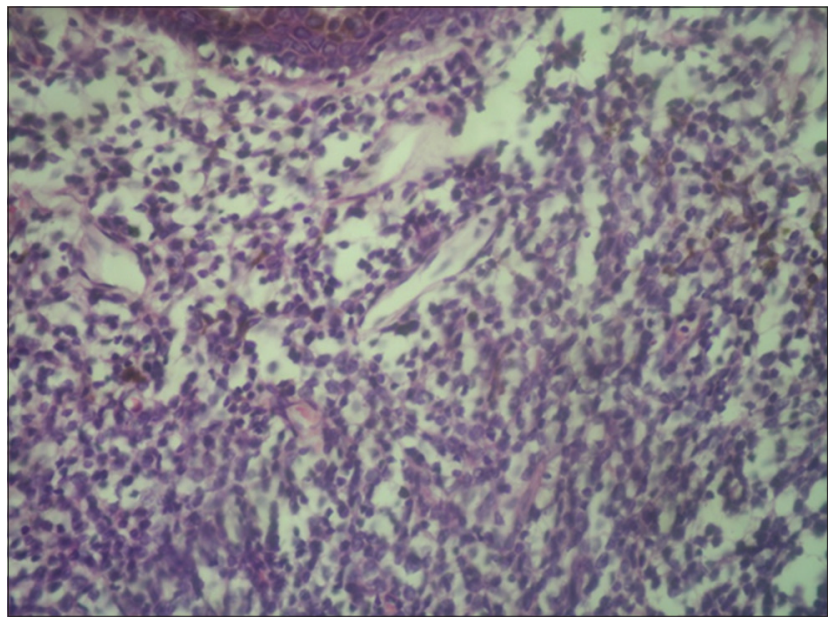

Microphotograph 3 : H\&E: 20x10X: Dense dermal mononuclear infiltrate with epidermotropism in mycosis fungoides

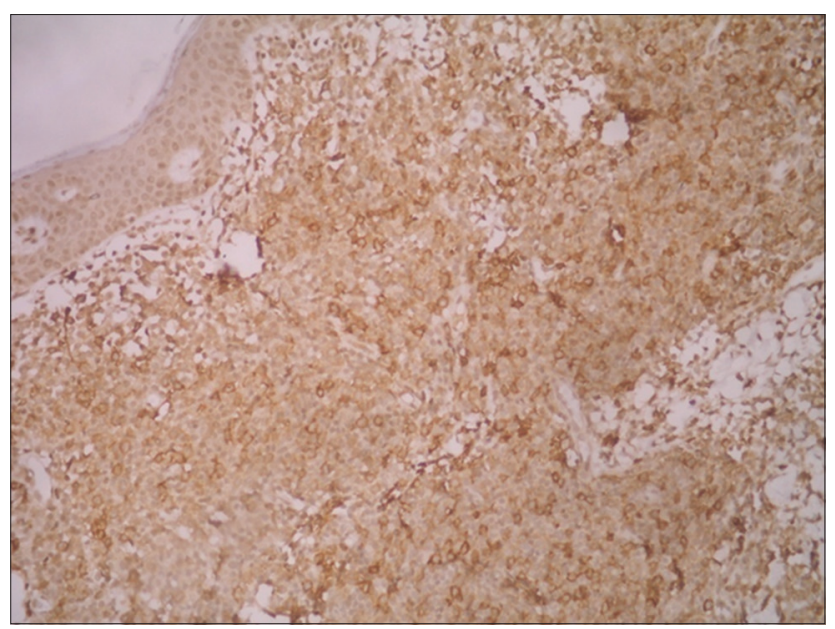

Microphotograph 4: Immunohistochemistry (CD 3): 20x10X: Cytoplasmic positivity in mycosis fungoides 
an incidence of 1-2/100,000 population. ${ }^{1}$ A prospective study done by Sehgal and Srivastava in India determined the incidence to be 35 per 100,000 dermatologic patients, ${ }^{2}$ while another study by Hasan and Jansen also estimated the annual incidence to be 1 to 2 per 100,000 population. ${ }^{3}$ There is a male predominance in most studies with a male-to-female ratio ranging from 2:1 to 4:1 and the mean age between 40 to 60 years. ${ }^{2}$ This is similar to our study where the male-to-female ratio was 1.5:1 with mean age of 38.7 years. Erythroderma is rarer in children where it accounts for approximately $0.1 \%$ of cases attending pediatric dermatology clinics. ${ }^{4,5}$ The youngest patient in our study was 14 year male who was diagnosed as a case of erythrodermic psoriasis.

A major challenge lies in determining the etiology of erythroderma. A pre existing dermatosis is the single most common cause of erythroderma as determined by most published series (Table 3). ${ }^{2,6-8}$ The most common cause of these dermatosis in Spanish, Middle Eastern and Indian studies include psoriasis and eczema..$^{6,7,9-12}$ The triggers for precipitating erythroderma in psoriatic patients are withdrawal of systemic or topical glucocorticoids, use of systemic medications like lithium and antimalarials, phototherapy burns, infection and systemic illnesses. ${ }^{13}$ Drug reactions leading to ED were seen in $11.2 \%$ cases in study by Rym et al and $12 \%$ cases by Bandyaopadhyay et al, however in our study we found drug reactions in $32.7 \%$ cases. ${ }^{6,14}$ No particular association was seen with winter season as also found in study by Hulmani et al. ${ }^{15}$ The laboratory findings were non contributory similar to the study by Pal and Haroon. ${ }^{16}$ In patients with no history of underlying skin disease and who denies any history of drug intake, the diagnosis is more difficult and such cases are almost always biopsied, although in such cases the histopathology is usually not rewarding and shows subacute or chronic dermatitis with psoriasiform reaction. Stage of the disease should be kept in mind while interpreting skin biopsy. In the acute stage spongiosis and parakeratosis are prominent, while in chronic stage, acanthosis and elongated rete ridges are seen. ${ }^{16}$ Despite the clinical presentation of erythroderma being relatively uniform, histopathological characteristics of underlying lesion are usually distinctive. ${ }^{17}$ The exact underlying pathogenesis of ED is not clear.
It is believed that there may be role play of cytokines, cell adhesion molecules including interleukins 1 and 2, intercellular adhesion molecules (ICAM-1) and Tumor Necrosis Factor (TNF). ${ }^{18}$ Their interactions lead to a high epidermal turnover rate causing increased mitotic activity and increased absolute number of germinative skin cells. This is also associated with loss of epidermal cells together with superficial loss of protein and folate. ${ }^{19}$ Benign (psoriasis, dermatitis, drug induced) and malignant (Sezary syndrome, MF) forms of erythroderma show similar immunophenotypic characteristics as studied by Abel et al..$^{20}$ Immunohistochemical studies done by Sigurdsson et al showed the dermal infiltrate in Sezary syndrome exhibiting T-helper-2 cytokine profile while in benign erythrodermas there was T-helper-1 cytokine profile. This proves that though clinically similar, these patients have different underlying pathogenic mechanisms. ${ }^{21}$

The principles of management are to maintain skin moisture, avoid scratching, avoid precipitating factors, applying topical steroids and treating the underlying cause and complications. Once the acute irritated state of the skin is improved, further treatment can be targeted at the underlying etiology. ${ }^{22}$ The outcome is unpredictable in idiopathic erythroderma and the course is marked by multiple exacerbations with prolonged requirement of glucocorticoid therapy.

In initial documented series, the recorded death rate due to erythroderma varied from 18 to $64 \% .^{2}$ No mortality was reported in our hospital and this supports Hasan and Jasen's view that erythroderma does not pose a significant risk to the patient's life. ${ }^{3}$

\section{CONCLUSION}

Erythroderma can be caused by a variety of underlying dermatosis, infections and systemic diseases. Since clinical features are identical irrespective of the underlying cause and laboratory findings pointing to a specific diagnosis may not be rewarding, the clinician should take a detailed history supported by ancillary investigations. However for definite clinicopathological correlation, multiple skin biopsies may be needed followed by close follow up and

\begin{tabular}{|c|c|c|c|c|c|c|c|c|c|}
\hline Causes & $\begin{array}{c}\text { Hasan \& } \\
\text { Jansen } \\
1983^{3}\end{array}$ & $\begin{array}{c}\text { Sehgal \& } \\
\text { Srivastava } \\
1986^{2}\end{array}$ & $\begin{array}{c}\text { Botella } \\
\text { estrad et al } \\
1994^{10}\end{array}$ & $\begin{array}{l}\text { Sigudssson } \\
\text { et al } 1996^{1}\end{array}$ & $\begin{array}{c}\text { Pal \& Haroon } \\
1998^{11}\end{array}$ & $\begin{array}{c}\text { Maryam } \\
\text { Akhyani } \\
2004^{7}\end{array}$ & $\begin{array}{c}\text { Yuan et al } \\
2010^{12}\end{array}$ & $\begin{array}{c}\text { Li J, Zheng HY } \\
\mathbf{2 0 1 2}^{8}\end{array}$ & $\begin{array}{c}\text { Present } \\
\text { study } \\
2014\end{array}$ \\
\hline Drug reaction & 22 & 24.7 & 16 & 5 & 5.5 & 21.6 & 17.0 & 12.6 & 32.7 \\
\hline $\begin{array}{l}\text { Psoriasis/ pre-existing } \\
\text { dermatosis }\end{array}$ & 42 & 62.5 & 62.5 & 53 & 74.4 & 57.9 & 72.0 & 70.7 & 17.2 \\
\hline Idiopathic & 32 & 22.5 & 9 & 26 & 14.6 & 7.2 & 6.1 & 14.2 & 10.3 \\
\hline Malignancy & 4 & 12.5 & 12.5 & 13 & 5.5 & 11.3 & 4.9 & 2.3 & 3.4 \\
\hline
\end{tabular}


repeated evaluation. Despite the homogeneity of clinical expression of erythroderma, diagnostic histopathological features of the underlying disease are retained in most cases. Hospitalization is needed for initial evaluation and treatment. Prognosis of erythroderma is dependent on underlying etiology.

\section{REFERENCES}

1. Sigurdsson V, Steegmans $\mathrm{PH}$ and Van Vloten WA. The incidence of erythroderma: a survey among all dermatologists in The Netherlands. J Am Acad Dermatol 2001; 45:675-678.

2. Sehgal VN and Srivastava G. Exfoliative dermatitis: A prospective study of 80 patients. Dermatologica1986; 173(6):278-284.

3. Hasan $T$ and Jansen CT. Erythroderma: a follow-up of fifty cases. J Am Acad Dermatol 1983; 8:836-840.

4. Sarkar R and Garg VK. Erythoderma in children. Ind J Dermatol Venereol Leprol 2010;76:341-347.

5. Sarkar R, Basu S and Sharma RC. Neonatal and infantile erythrodermas. Arch Dermatol 2001;137:822-823.

6. Rym BM, Mourad M, Bechir Z, Dalenda E, Faika C, ladh AM, et al. Erythroderma in adults: a report of 80 cases. Int J Dermatol 2005; 44(9): 731-735.

7. Akhyani M, Ghodsi ZS, Toosi S and Dabbaghian H. Erythroderma: a clinical study of 97 cases. BMC Dermatol 2005; 5: 5

8. Li J and Zheng HY. Erythroderma: a clinical and prognostic study. Dermatology 2012; 225(2):154-162.

9. Balasubramaniam $\mathrm{P}$ and Berth-Jones J. Erythroderma: $90 \%$ skin failure. Hosp Med 2004;65(2):100-102.

10. Botella-Estrada R, Sanmartin O, Oliver V, Febrer I and Aliaga A.
Erythroderma: A clinicopathological study of 56 cases. Arch Dermatol 1994;130(12):1503-1507.

11. Pal S and Haroon TS. Erythroderma: A clinico-etiological study of 90 cases. Int J Dermatol 1998; 37(2):104-107.

12. Yuan XY, Guo JY, Dang YP, Qiao L and Liu VV. Erythroderma: A clinic-etiological study of 82 cases. Eur J Dermatol 2010; 20(3):373-377.

13. Rubins AY, Hartmane IV, Lielbriedis $Y M$ and Schwartz RA. Therapeutic options for erythroderma. Cutis 1992; 49(6):424-426.

14. Bandyaopadhyay D, Chowdhury $S$ and Roy A. Seventy five cases of exfoliative dermatitis. Ind J Dermatol 1999; 44:55-57.

15. Hulmani M, Nanda Kishore B, Bhat RM, Martis J, Kamath $G$ and Srinath MK. Clinico-etiological study of 30 erythroderma cases from tertiary center in South India. Indian Dermatol Online J 2014;5: 25-29.

16. Sehgal VN, Srivastava G and Sardana K. Erythroderma/ exfoliative dermatitis: A synopsis. Int J Dermatol 2004; 43: 39-47.

17. Zip C, Murray $S$ and Walsh NM. The specificity of histopathology in erythroderma. J Cutan Pathol 1993; 20(5):393-398.

18. Wilson DC, Jester JD and King LE. Erythroderma: an exfoliative dermatitis. Clin Dermatol 1993;11:67-72.

19. Hild DH. Folate loss from the skin in exfoliative dermatitis. Arch Intern Med 1969; 123:51-57.

20. Abel EA, Lindae ML, Hoppe RT and Wood GS. Benign and malignant forms of erythroderma. J Am Acad Dermatol 1988; 19:1089-1095.

21. Sigurdsson V, Toonstra J, Bihari IC, Bruijnzeel-Koomen CAFM, Vloten WAV and Thepen T. Interleukin-4 and Interferon-gamma expression of the dermal infiltrate in patients with erythroderma and mycosis fungoides-an immunohistochemical study. J Cutan Pathol 2000; 27: 429-435.

22. Karakayli G, Beckham G, Orengo I and Rosen T. Exfoliative dermatitis. Am Fam Physician 1999; 59: 625-630.

Authors Contribution:

NS, RJ, AJ, SA: concept, design, manuscript preparation, editing and review, NS, KY: data analysis.

Source of Support: Nil, Conflict of Interest: None declared. 